\title{
Effect of Perceived Organizational Support on Fatigue of Chinese Nurses during the COVID-19 Pandemic: Resilience as a Mediator
}

\author{
$\mathrm{Na} \mathrm{Zhang}^{1}$, Dingxin $\mathrm{Xu}^{2}$, Jingjing $\mathrm{Li}^{3{ }^{3 *}}$ and Zhenxing Gong ${ }^{4}$ \\ ${ }^{1}$ School of Economics and Management, Beijing Information Science and Technology University, Beijing, 100192, China \\ ${ }^{2}$ School of Nursing, Jinan University, Guangzhou, 510632, China \\ ${ }^{3}$ College of Economics and Management, Beijing University of Technology, Beijing, 100124, China \\ ${ }^{4}$ School of Business, Liaocheng University, Liaocheng, 252000, China \\ ${ }^{*}$ Corresponding Author: Jingjing Li. Email: lijj@bjut.edu.cn
}

Received: 10 February 2021 Accepted: 03 April 2021

\begin{abstract}
As working for the nurse is believed to be one of the most stressful professions, nurses are particularly at risk of experiencing fatigue. Especially during the COVID-19 pandemic, fatigue among nurses may affect physical and mental health seriously, which is attracting increasing attention of researchers and clinical practitioners to find effective prevention measures to alleviate nurses' fatigue. This study aims to investigate the mediational effect of resilience on the relationship between nurses' perceived organizational support and fatigue. A total of 476 nurses from secondary and above hospitals in Hebei province, China during March and April in 2020, were investigated with Perceived Organizational Support Scale, Resilience Scale and Work Fatigue Inventory. Structural equation modeling was conducted to explore the mechanisms of nurses' perceived organizational support on fatigue. Results revealed that perceived organizational support can decrease the nurses' mental/physical/emotional fatigue through the mediating role of resilience. These findings guide for hospital managers to identify effective prevention strategies to alleviate the fatigue of clinical nurses.
\end{abstract}

\section{KEYWORDS}

Perceived organizational support; resilience; fatigue; mediator; nurse

\section{Introduction}

As a complex and general phenomenon, nurse fatigue is a multidimensional condition with emotional, physiologic, mental, and sensory components that occurs as a consequence of excessive work demands and stressors from nurses' work tasks, environment, and schedules with insufficient opportunity for recovery $[1,2]$. Especially during the COVID-19 pandemic, because of working with high intensity, nurses are enduring tremendous pressure from around; they have high risk of becoming infected without adequate protection, and feel loss of control and inexperienced in combating the disease. Besides of overwork, they get negative feedback from patients and perceived stigma sometimes. Additionally, their lifestyle has changed greatly and facing work-family conflict [3,4]. All these stressors have been consistently associated with increased nurse fatigue and an increased risk of medical error or near error that threaten the safety of patients [5]. Therefore, fatigue is a critical issue that jeopardizes a nurse's capability of 
providing safe and effective nursing to patients, and it is of great significance to explore the factors affecting nurse fatigue to help formulate relevant management measures in hospitals.

\section{Background}

Existing research on fatigue has focused on the following influencing factors. First, many scholars have explored the relationship between individual-related factors and fatigue. Examples of personal characteristics include age, gender, academic degree, and marital status [6,7]; Further, examples of health factors that have been studied include an unhealthy diet [8], sleep duration and quality [7,9], and depression and anxiety [10]. Second, some studies have found that work-related factors are associated with nurse fatigue; nurses with long work hours [11], more work shifts [12], and high workplace demands were found to have increased levels of fatigue [13]. While previous research has identified many factors that may result in fatigue, limited information is available regarding positive resources to manage nurse fatigue [14].

Recently, psychologists have identified resilience as the positive psychological capability that helps an individual to rebound, "bounce back", or return to a normal state from adverse circumstances, such as disappointment, conflict, hard times, and failure, or even experience growth, positive events, and increased responsibility $[15,16]$. Some studies have shown that resilience works as a protective factor against fatigue [17,18]. Unfortunately, previous research has been limited by mainly focusing on one or two types of fatigue. For instance, Qiu et al. [14] found that resilience has negative effect on physical and mental fatigue among Chinese doctors. Alsharif [19] found that nurses with low resilience were more likely to experience high emotional fatigue. In Jeon et al.'s [17] research, resilience was found to be a significant negative predictor of physical fatigue.

However, unlike burnout, which usually applies on the psychological level, the fatigue that we focus on is a multidimensional condition with emotional, physical, and mental component. As nurses often work shifts and long hours, cope with the social competitions and take social responsibility, physical fatigue and mental fatigue are prevalent among nurses [20]. During the COVID-19 epidemic, nurses are in short supply, and they must take high workload, which lead to high physical fatigue. Additionally, traumatic events such as the death of patients and even their family and friends, that make nurses are more likely to experience mental and emotional fatigues. Given the special job characteristics of nurses, fatigue they experienced came from multiple aspects. Besides consistently exposed to physical and mental demands, they constantly experienced helplessness and anger in response to the stress they feel watching patients go through devastating illnesses or trauma [2], it is likely that physical fatigue, mental fatigue, and emotional fatigue dimensions are all present, and should be taken into account simultaneously [21]. As very little research has sought to integrate these three dimensions of fatigue, this represents a significant gap in our understanding of how resilience can reduce nurses' physical, mental, and emotional fatigue.

Resilience is key to enhancing nursing quality and sustainability of medical and health institutions. Yet ways of identifying and improving resilience have been difficult and complex [16]. In recent decades, research on resilience has focused on personal attributes or strengths that assist individuals in surviving adverse events [22]. Recently, scholars have paid more attention to the substantial contribution of support systems, which play a critical role in helping individuals resist pressures and prosper in harsh conditions [16,23]. That is to say, these resilient attributes can be developed by supportive environments [22].

According to Eisenberger et al. [24], perceived organizational support (POS) is the employees' belief concerning the extent to which the organization values their contributions, cares about their well-being, and fulfills their socio-emotional needs. As an indicator of the availability of organizational support, POS reflects how much an organization appreciates its employees [25], which usually causes positive work and mental health outcomes [14,26,27]. One study on Chinese doctors found that POS has negative effect on physical and mental fatigue [14]. Another study in Korea showed that organizational support had a significant negative effect on the perceived fatigue of seafarers [28]. Moreover, Allen [29] shown that 
organizational support was one of the most significant factors in emotional fatigue among child welfare workers. Given that it is an external resource, the protective effect of POS against fatigue is inevitably influenced by some other internal factors. However, integrated research that explains the mechanism of how and why the positive resources affect fatigue is still limited.

The Conservation of resources (COR) theory, proposed by Hobfoll [30], indicates that job resources (both internal and external resources), when readily available, can only accumulate and therefore lead to positive outcomes. That is to say, as an external coping resource in workplaces, organizational support acts can lead to accumulation of personal internal resources such as resilience, which in turn results in positive outcomes such as less fatigue [31]. In a survey research operated by Liu et al. [32], resilience was found to mediate the association between POS and depression among correctional officers, and the same finding was obtained by Liu et al. [33]. Moreover, resilience was found to be a mediator of the relationship between POS and anxious among underground coal miners [33]. Other research indicated that resilience could partially mediate the association of effort-reward imbalance with fatigue in Chinese nurses [34]. However, whether resilience mediates the relationship between POS and fatigue has not been tested among Chinese nurses. It is important to examine the positive effects of POS and resilience to develop specific preventions for physical, mental, and emotional fatigue.

From the above discussion, this study hypothesizes as follows:

H1: POS is negatively related to physical, mental, and emotional fatigue.

$\mathrm{H} 2$ : POS is positively associated with resilience.

H3: Resilience has negative effects on physical, mental, and emotional fatigue.

H4: Resilience mediates the relationship between POS and physical, mental, and emotional fatigue.

The hypothesized model for the study is shown in Fig. 1.

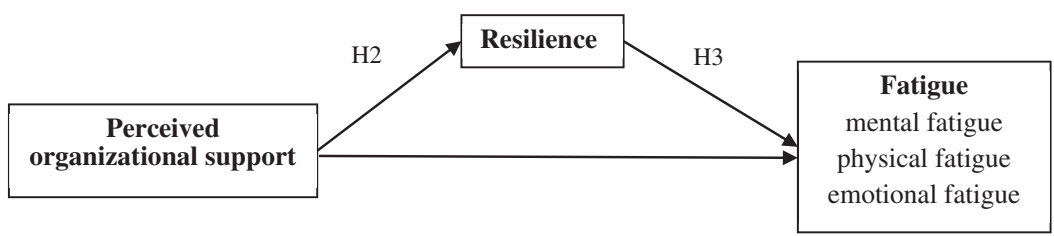

Figure 1: Overall conceptual framework

\section{Methods}

\subsection{Design and Data Collection}

Based on quantitative design and investigation, this study adopted a random and convenience sampling design. Data collection was conducted from March to April 2020, during the COVID-19 pandemic, in Hebei Province, China. All participants were clinical nurses who were randomly selected from morning, evening, and night shifts.

The second author distributed questionnaires in person to these nurses in the duration of March and April 2020. After the researcher introduced the purpose, risks, and benefits of this study, the participants expressed verbal informed consent that the participation was of their own free will and did not collect personally identifiable information. With the permission of the head nurse, all participants completed the questionnaire during their working hours. Respondents were acquainted with the fact that the purpose of the survey was to have better understanding of the nurses. Dedicated letterboxes will be set up in each unit to collect completed questionnaires. At last, the filled questionnaires were collected by the second author. 
The remaining 476 valid questionnaires were employed in the study after eliminating 74 invalid questionnaires. Of all the nurses in the survey, 93.9\% were female, $88.2 \%$ were of young (less than 40 years old), $80.1 \%$ had a college education (bachelor's degree or higher), and $89.1 \%$ had less than 20 years of work experience. Notably, $68.3 \%$ of the participants had some of their colleagues go to Hubei Province (which was the first to have COVID-19 cases and had the most reported cases in the entire country) to assist in the fight against the pandemic.

\subsection{Measures}

Following Liu et al. [34] research, the Survey of Perceived Organizational Support created by Eisenberger et al. [24] was administered to measure nurses' POS. The Chinese version of this scale was developed and verified by Ling et al. [35]; it consists of 8 items (e.g., "Your organization cares about your well-being") scored on a five-point scale, range from $1=$ strongly disagree to $5=$ strongly agree, with higher scores indicating a higher level of nurse's POS. In previous research among different kinds of Chinese clinical groups, the scale has satisfactory reliability and validity all the time [14,34]. For this study, the Cronbach's $\alpha$ was 0.904 .

Yu et al. [36] developed the Chinese version of the Connor-Davidson Resilience Scale (CD-RISC), which was conducted to measure nurse's resilience. The scale consists of 25 items (e.g., "Can handle unpleasant feelings", "Able to adapt to change" and "You can achieve your goals"), and uses a fivepoint ranging scale $(1=$ not true at all, $5=$ true nearly all of the time), with higher scores reflecting greater nurse's resilience. This scale has been widely applied in Chinese studies and has good reliability and validity $[14,34,36]$. In the research, the CD-RISC also has shown good reliability with Cronbach's $\alpha$ was 0.931 .

Frone et al. [37] formulated the Three-Dimensional Work Fatigue Inventory (3D-WFI) to assess fatigue, and Chu et al. [38] translated and validated the Chinese version, which was consist of 18 items with 3 dimensions: mental fatigue (e.g., "Feel mentally exhausted at the end of the workday"), physical fatigue (e.g., "Feel physically drained at the end of the workday"), and emotional fatigue (e.g., "Have difficulty showing and dealing with emotions at the end of the workday"). For each item, the participants were asked to choose the rating that most accurately reflected how often they experienced that aspect of fatigue from (1) never to (5) every day. Higher scores indicated higher levels of fatigue. The Cronbach's $\alpha$ for mental fatigue, physical fatigue, and emotional fatigue in this study was 0.959 , 0.932 , and 0.953 , respectively.

\subsection{Data Analysis}

Mplus 7.4 statistical software was utilized for data analysis. We initially obtained the means, standard deviations, and correlation values among these variables. Subsequently, we selected structural equation modeling to examine the hypothesized model. The two-step analytical strategy [39] was adopted to test the mediation effect. Firstly, the confirmatory factor analysis (CFA) was conducted to test the measurement model. Secondly, we used maximum likelihood estimation to test the structural model. Bootstrap analysis was used to test the mediating effect of resilience with 2,000 iterations.

\section{Results}

\subsection{Preliminary Analyses}

Tab. 1 provides the means (M), standard deviations (SD), and correlation coefficients for and among all variables. The results of correlation analysis indicated that none of the demographic variables except gender and marriage status were correlated with dependent variables. In contrast, there were significant correlations between independent variables and dependent variables. Specifically, POS was positively correlated with resilience $(r=0.384, P<0.01)$ but negatively correlated with mental fatigue $(r=-0.359, P<0.01)$, 
physical fatigue $(r=-0.396, P<0.01)$, and emotional fatigue $(r=-0.409, P<0.01)$. In addition, resilience had a negative relationship with mental fatigue $(r=-0.372, P<0.01)$, physical fatigue $(r=-0.424$, $P<0.01)$, and emotional fatigue $(r=-0.436, P<0.01)$.

Table 1: Means, standard deviations, and correlations

\begin{tabular}{llllllll}
\hline & Mean & SD & 1 & 2 & 3 & 4 & 5 \\
\hline 1. Resilience & 3.62 & 0.55 & 1 & & & & \\
2. Mental fatigue & 3.58 & 1.09 & $-0.372^{* *}$ & 1 & & & \\
3. Physical fatigue & 3.19 & 1.24 & $-0.424^{* *}$ & $0.870^{* *}$ & 1 & & \\
4. Emotional fatigue & 2.78 & 1.20 & $-0.436^{* *}$ & $0.741^{* *}$ & $0.862^{* *}$ & 1 & \\
5. Perceived organizational support & 3.57 & 0.61 & $0.384^{* *}$ & $-0.359^{* *}$ & $-0.396^{* *}$ & $-0.409^{* *}$ & 1 \\
\hline
\end{tabular}

Note: ${ }^{*}$ Correlation is significant at the 0.01 level (2-tailed); ${ }^{*}$ Correlation is significant at the 0.05 level (2-tailed).

\subsection{Measurement Model}

From the data in Tab. 2, results of CFA indicated that the proposed model, which comprised five latent constructs of resilience, mental fatigue, physical fatigue, emotional fatigue, and POS (Model 1) had an excellent fit to the data, $\chi^{2} / \mathrm{df}=2.96, P<0.000 ;$ TLI $=0.901$, CFI $=0.907$, RMSEA $=0.06$, $\mathrm{SRMR}=0.046$, and the lowest values for AIC and BIC exhibited the greatest fit of the Model 1 $(\mathrm{AIC}=44950.923, \mathrm{BIC}=45554.909)$. To mitigate common method bias concerns, we then compared the hypothesized measurement model with a three-factor model (Alternative Model 1), in which mental fatigue, physical fatigue, and emotional fatigue were combined into one factor. The two-factor model (Alternative Model 2), in which resilience and POS were collapsed into one factor and all the dependent variables (mental fatigue, physical fatigue, and emotional fatigue) were collapsed into another factor was tested, as well as a one-factor model (Alternative Model 3) with each indicator loaded on a single factor was tested as another alternative measurement model. All the alternative models had poorer fit than the proposed measurement model (Model 1) to the data.

Table 2: Fit statistics and indices for different models

\begin{tabular}{|c|c|c|c|c|c|c|c|c|c|}
\hline Model & Description & $\chi^{2}$ & $\begin{array}{l}\chi^{2} / \\
d f\end{array}$ & $A I C$ & $B I C$ & $T L I$ & $C F I$ & $S R M R$ & RMSEA \\
\hline Model 1 & $\begin{array}{l}5 \text { factors: resilience, mental fatigue, } \\
\text { physical fatigue, emotional fatigue, } \\
\text { and perceived organizational support }\end{array}$ & $2512.80 * * *$ & 2.69 & 44950.923 & 45554.909 & 0.901 & 0.907 & 0.046 & 0.060 \\
\hline $\begin{array}{l}\text { Alternative } \\
\text { Model } 1\end{array}$ & $\begin{array}{l}3 \text { factors: resilience, perceived } \\
\text { organizational support, and all the } \\
\text { outcome variables combined into } \\
\text { one factor }\end{array}$ & $3306.92 * * *$ & 3.51 & 45731.046 & 46305.873 & 0.853 & 0.861 & 0.050 & 0.073 \\
\hline $\begin{array}{l}\text { Alternative } \\
\text { Model } 2\end{array}$ & $\begin{array}{l}2 \text { factors: causal variables (resilience } \\
\text { and perceived organizational } \\
\text { support) and outcome variables } \\
\text { (mental fatigue, physical fatigue, and } \\
\text { emotional fatigue) }\end{array}$ & $4933.64 * * *$ & 5.23 & 47353.770 & 47920.266 & 0.753 & 0.765 & 0.089 & 0.094 \\
\hline $\begin{array}{l}\text { Alternative } \\
\text { Model } 3\end{array}$ & $\begin{array}{l}1 \text { factor: all items loading on the } \\
\text { same factor }\end{array}$ & $7777.38 * * *$ & 8.23 & 50195.508 & 507.57 .839 & 0.578 & 0.597 & 0.147 & 0.123 \\
\hline
\end{tabular}


Additionally, the results in Tab. 3 showed that the construct reliabilities (CR) ranged from 0.904 to 0.960 , the average variance extracted (AVE) ranged from 0.421 to 0.800 , and all scale items had substantial loading on their designated constructs. According to Gerbing et al. [40], CR should exceed 0.70, and AVE should exceed 0.40. The results in this study exceed the recommended value and supported the verification for convergent validity. Besides, the AVE value was higher than the square of correlation coefficient with other constructs showing satisfactory of discriminant validity.

Table 3: Convergent and discriminant analysis

\begin{tabular}{lllllll}
\hline & AVE & CR & 1 & 2 & 3 & 4 \\
\hline 1. Perceived organizational support & 0.545 & 0.904 & & & & \\
2. Resilience & 0.421 & 0.932 & 0.15 & & & \\
3. Mental fatigue & 0.705 & 0.935 & 0.13 & 0.14 & & \\
4. Physical fatigue & 0.800 & 0.960 & 0.16 & 0.18 & 0.76 & \\
5. Emotional fatigue & 0.777 & 0.954 & 0.17 & 0.19 & 0.55 & 0.74 \\
\hline
\end{tabular}

Note: AVE: Average Variance Extracted; CR: Construct Reliability.

\subsection{Structural Model}

We firstly tested the direct paths from the POS to mental/physical/emotional fatigue, in the absence of resilience. The coefficients were showed to be significant. From the data in Tab. 4, POS had a significantly negative correlation with mental $(\beta=-0.264, P<0.001,95 \% \mathrm{CI}$ : $[-0.365,-0.167])$, physical $(\beta=-0.283$, $P<0.001,95 \% \mathrm{CI}:[-0.386,-0.188])$, and emotional fatigue $(\beta=-0.285, P<0.001,95 \% \mathrm{CI}:[-0.384$, $-0.189])$. Thus, H1 was supported. And then, a partially mediated model, with resilience as a mediator and direct paths from POS to mental/physical/emotional fatigue, showed a good fit: $\chi^{2} / \mathrm{df}=2.545$, $P<0.001$, CFI $=0.901$, RMSEA $=0.050$, SRMR $=0.050 . \mathrm{H} 2$, which posited that POS is positively associated with resilience, was also supported ( $\beta=0.411, P<0.001,95 \%$ CI: [0.323,0.501]). Resilience showed a significant negative correlation with mental $(\beta=-0.274, P<0.001,95 \% \mathrm{CI}$ : $[-0.380,-0.165])$, physical $(\beta=-0.322, P<0.001,95 \% \mathrm{CI}:[-0.425,-0.216])$, and emotional fatigue $(\beta=-0.343, P<$ $0.001,95 \% \mathrm{CI}:[-0.425,-0.239])$. These relationships supported H3.

Table 4: Standardized path coefficients

\begin{tabular}{lllll}
\hline \multicolumn{1}{c}{ Hypothesis } & Estimate $(95 \% \mathrm{CI})$ & $P$ & Remarks \\
\hline H1 perceived organizational support $\rightarrow$ mental fatigue & $-0.264(-0.365,-0.167)$ & $<0.001$ Supported \\
perceived organizational support $\rightarrow$ physical fatigue & $-0.283(-0.386,-0.188)<0.001$ Supported \\
perceived organizational support $\rightarrow$ emotional fatigue & $-0.285(-0.384,-0.189)<0.001$ Supported \\
H2 perceived organizational support $\rightarrow$ resilience & $0.411(0.323,0.501)$ & $<0.001$ Supported \\
H3 resilience $\rightarrow$ mental fatigue & $-0.274(-0.380,-0.165)<0.001$ Supported \\
resilience $\rightarrow$ physical fatigue & $-0.322(-0.425,-0.216)<0.001$ Supported \\
resilience $\rightarrow$ emotional fatigue & $-0.343(-0.425,-0.239)<0.001$ Supported \\
\hline
\end{tabular}

As shown in Tab. 5, all the bootstrap bias-corrected 95\%CIs excluded zero, indicating that the indirect effects of POS on mental/physical/emotional fatigue through resilience were significant. Mental fatigue $(\beta=-0.376)$ was predicted directly $(\beta=-0.264)$ and indirectly $(\beta=-0.112)$ by POS through resilience. Physical fatigue $(\beta=-0.415)$ was predicted directly $(\beta=-0.283)$ and indirectly $(\beta=-0.132)$ by POS 
through resilience. Emotional fatigue $(\beta=-0.426)$ was predicted directly $(\beta=-0.285)$ and indirectly $(\beta=-0.141)$ by POS through resilience. Furthermore, the proportion of resilience's mediation was $29.8 \%$ in the total effect of POS on mental fatigue, $31.8 \%$ in the total effect of POS on physical fatigue, and $33.1 \%$ in the total effect of POS on emotional fatigue. Thus, H4 was supported.

Table 5: Mediating effect analysis

\begin{tabular}{lcrc}
\hline Path & $\begin{array}{l}\text { Indirect } \\
\text { effects }\end{array}$ & S.E. $P$ & $95 \% \mathrm{CI}$ \\
\hline $\begin{array}{l}\text { perceived organizational support } \rightarrow \text { resilience } \rightarrow \text { mental } \\
\text { fatigue }\end{array}$ & -0.112 & $0.027<0.001 \quad \begin{array}{l}(-0.172, \\
-0.066)\end{array}$ \\
$\begin{array}{l}\text { perceived organizational support } \rightarrow \text { resilience } \rightarrow \text { physical } \\
\text { fatigue }\end{array}$ & -0.132 & $0.028<0.001 \quad \begin{array}{l}(-0.199, \\
-0.085)\end{array}$ \\
$\begin{array}{l}\text { perceived organizational support } \rightarrow \text { resilience } \rightarrow \\
\text { emotional fatigue }\end{array}$ & -0.141 & $0.028<0.001 \quad(-0.206$, \\
\hline
\end{tabular}

\section{Discussion}

\subsection{Interpreting the Findings}

Despite the considerable research attention that scholars have devoted to examining the influence factors of fatigue, existing research has primarily focused on individual or work-related factors, and finding positive resources to manage this adverse effect has been ignored. Additionally, given that there are three dimensions of fatigue (mental, physical, and emotional) and each of them reflects different aspects of nurses' fatigue, it is crucial to test the distinctive impact of various factors on the three elements. Unfortunately, researchers have focused mainly on physical and mental fatigue, while emotional fatigue has received less attention. Drawing upon conservation of resources theory, we developed and tested an integrated model confirming the positive factors in preventing and relieving the fatigue of Chinese nurses during the COVID-19 pandemic and found that resilience could mediate the relationship between POS and mental, physical, and emotional fatigue. These findings provide critical insights for both researchers and clinical practitioners, which are discussed thoroughly as follows.

Consistent with previous research, our results indicated that resilience is a positive psychological resource for nurses for coping with both physical and mental fatigue [14,17]. Furthermore, we found congruent evidence to support our hypothesis, with results demonstrating that resilience has a significant negative impact on emotional fatigue. The current findings line up with Rísquez et al. [41] and Alsharif's [19] results, in which nursing students who showed a higher level of resilience experienced less emotional fatigue, as well as Jin et al. [42] research, which found that resilience had a negative correlation with emotional fatigue. A possible explanation for these findings might be that when nurses have a higher level of resilience, they tend to show more emotional stability when faced with adversity in a constantly changing workplace environment $[34,43,44]$. Accordingly, resilience is a vital resource for alleviating all kinds of fatigue in nurses, whether it be mental, physical, or emotional fatigue.

As a kind of positive psychological capability, resilience can be developed through enhancing nursing knowledge and skills and practicing positive thinking $[45,46]$. Based on previous findings, management measures that improve nurses' resilience should be applied in hospitals, such as resilience training [47], implementing evidence-based resilience improvement programs [46], providing connections and worklife balance [48], and creating a caring, healing work environment [22]. 
Besides resilience, POS is a job resource that can help Chinese nurses cope with fatigue. Specifically, we found that POS not only had a direct effect on fatigue but also indirectly helped relieve fatigue through the mediating effect of resilience. These results suggest that nurse's perception of the organizational support becomes integrated into his or her positive personal resources, which in turn decrease his or her all kinds of fatigue. These results match those observed in earlier empirical studies, which reported that POS was a positive coping resource for work fatigue [14,49,50]. For example, in Liu et al. research [49], organizational support had negative effects on work-related fatigue, no matter it is acute fatigue or chronic fatigue. However, unlike Liu et al. [34] and Qiu et al. [14], in which the interactions of POS and resilience decreased fatigue, the findings of our study confirmed the positive impact of POS on resilience, and then, POS reduced fatigue both directly and indirectly through resilience. Our results highlight that nurses' resilient attributes can be developed through supportive environments (i.e., organizational support). Simultaneously, our results can be interpreted by COR theory to indicate that the availability of job resources (i.e., POS) leads to increasement of personal resources (i.e., resilience), which subsequently produce positive psychological outcomes such as alleviating of fatigue. Therefore, our results highlight that continuous attention has been paid by nursing researchers and managers to improving nurses' POS, such as providing supportive settings, making reasonable work arrangements, giving adequate help, treating nurses fairly, affirming nurses' contributions, and caring about their well-being [33,51,52].

COVID-19 epidemic has added to the uncertainty and crisis in workplace, especially for Chinses nurses, due to the nursing shortage and high workload. Not only do they have to handle physical and mental stress in work, but also deal with traumatic events, such as illness and death. They are more likely to experience fatigue than others due to the intensive work and high risk of infection. Therefore, it is urgent for nurses to seek organizational support to reduce their fatigue. This study found that organizational support can enhance nurses' resilience, and then relieve their fatigue, which contribute both the theoretical and practical research in times of COVID-19.

In addition, to reduce the risk of negative psychological consequences of the COVID-19 epidemic and promote social stability, the National Health Commission of China has incorporated psychological crisis intervention into the overall deployment of disease prevention and issued more than 10 documents related to mental health [53]. Our study timely reflected the mental health and fatigue of current nurses in China. Therefore, these results provide new ideas for nursing managers in improving nurses' resilience and reducing mental, physical, and emotional fatigue. In turn, protecting the mental health of nurse is an important part of public health measures to fight the COVID-19 epidemic.

\subsection{Limitations}

Although the counteractive mechanism of fatigue that was derived from the positive perspective was confirmed by our data, there are still some limitations of the research. One potential limitation is that since all variables were self-reported, this survey method may suffer from the response bias of each respondent [54]. Future studies should integrate qualitative and quantitative research methods to obtain more reliable data to test the factors of fatigue. Second, all the subjects were from secondary and above hospitals in the same province, while nurses from community and rural hospitals and institutions in other provinces were not employed in this study. In the future, nurses from various types of hospitals should be studied to guarantee to the generalizability of the results. Last but not the least, although we analysed the antecedent variables of kinds of nurses' fatigue through constructing cross-sectional study, it cannot explain the causal relationship between these variables strongly. In the future, longitudinal methods are needed to confirm the results of the present study. 


\section{Conclusion}

Our study demonstrated that perceived organizational support could decrease the nurses' mental/physical/emotional fatigue through the mediating role of resilience. Hospital managers should identify effective prevention strategies to alleviate the fatigue of clinical nurses.

As mentioned above, because fatigue is a pervasive phenomenon in the nursing workplace that jeopardizes a nurse's ability to provide safe and effective care to patients, nursing supervisors should pay more attention to provide more organizational support and improve nurses' resilience to reduce nurses' physical, mental, and emotional fatigue. This study contributed to understanding the buffering effect of perceived organizational support and resilience on nurse fatigue.

Acknowledgement: We are grateful to the hospitals and their employees who participated in this study.

Funding Statement: This work was funded by the National Natural Science Foundation of China Project (71901031, 71801120, 71801017), the Social Science Program of the Beijing Municipal Education Commission Project (SM201911232006), the Development of University Connotation Scientific Research Level Promotion Project at Beijing Information Science and Technology University (2019KYNH215), and the China Postdoctoral Science Foundation (2020M680282).

Conflicts of Interest: The authors declare that they have no conflicts of interest to report regarding the present study.

\section{References}

1. Barker, L. M., Nussbaum, M. A. (2011). Fatigue, performance and the work environment: A survey of registered nurses. Journal of Advanced Nursing, 67(6), 1370-1382. DOI 10.1111/j.1365-2648.2010.05597.x.

2. Barker, L. M., Nussbaum, M. A. (2013). Dimensions of fatigue as predictors of performance: A structural equation modeling approach among registered nurses. IIE Transactions on Occupational Ergonomics and Human Factors, 1(1), 16-30. DOI 10.1080/21577323.2011.637153.

3. Qi, L., Cai, D., Liu, B., Feng, T. (2020). Effect of workplace ostracism on emotional exhaustion and unethical behaviour among Chinese nurses: A time-lagged three-wave survey. Journal of Advanced Nursing, 150(1), 1. DOI 10.1111/jan.14405.

4. Kang, L., Li, Y., Hu, S., Chen, M., Yang, C. et al. (2020). The mental health of medical workers in Wuhan, China dealing with the 2019 novel coronavirus. Lancet Psychiatry, 7(3), e14. DOI 10.1016/S2215-0366(20)30047-X.

5. Härmä, M., Karhula, K., Puttonen, S., Ropponen, A., Koskinen, A. et al. (2019). Shift work with and without night work as a risk factor for fatigue and changes in sleep length: A cohort study with linkage to records on daily working hours. Journal of Sleep Research, 28(3), e12658. DOI 10.1111/jsr.12658.

6. Smith-Miller, C. A., Shaw-Kokot, J., Curro, B., Jones, C. B. (2014). An integrative review fatigue among nurses in acute care settings. Journal of Nursing Administration, 44(9), 487-494. DOI 10.1097/NNA.0000000000000104.

7. Cai, S., Lin, H., Hu, X., Cai, Y., Chen, K. et al. (2018). High fatigue and its associations with health and work related factors among female medical personnel at 54 hospitals in Zhuhai, China. Psychology, Health \& Medicine, 23(3), 304-316. DOI 10.1080/13548506.2017.1361038.

8. Fang, J., Kunaviktikul, W., Olson, K., Chontawan, R., Kaewthummanukul, T. (2008). Factors influencing fatigue in Chinese nurses. Nursing \& Health Sciences, 10(4), 291-299. DOI 10.1111/j.1442-2018.2008.00407.x.

9. Åkerstedt, T., Wright, K. P. (2009). Sleep loss and fatigue in shift work and shift work disorder. Sleep Medicine Clinics, 4(2), 257-271. DOI 10.1016/j.jsmc.2009.03.001.

10. Garg, H., Bush, S., Gappmaier, E. (2016). Associations between fatigue and disability, functional mobility, depression, and quality of life in people with multiple sclerosis. International Journal of MS Care, 18(2), 71-77. DOI 10.7224/1537-2073.2015-013. 
11. Johnston, D. W., Allan, J. L., Powell, D. J. H., Jones, M. C., Farquharson, B. et al. (2018). Why does work cause fatigue? A real-time investigation of fatigue, and determinants of fatigue in nurses working 12-hour shifts. Annals of Behavioral Medicine, 53(6), 551-562. DOI 10.1093/abm/kay065.

12. Adriaenssens, J., Gucht, V. D., Doef, M. V. D., Maes, S. (2011). Exploring the burden of emergency care: Predictors of stress-health outcomes in emergency nurses. Journal of Advanced Nursing, 67(6), 1317-1328. DOI 10.1111/j.1365-2648.2010.05599.x.

13. Raftopoulos, V., Charalambous, A., Talias, M. (2012). The factors associated with the burnout syndrome and fatigue in Cypriot nurses: A census report. BMC Public Health, 12(1), 457. DOI 10.1186/1471-2458-12-457.

14. Qiu, T., Yang, Y., Liu, C., Tian, F., Gu, Z. et al. (2020). The association between resilience, perceived organizational support and fatigue among Chinese doctors: A cross-sectional study. Journal of Affective Disorders, 265(1), 85-90. DOI 10.1016/j.jad.2020.01.056.

15. Luthans, F. (2007). Hope, optimism, and other business assets; Why "psychological capital" is so valuable to your company. Comportamento Organizacional e Gestão, 13, 137-142.

16. Epstein, R. M., Krasner, M. S. (2013). Physician resilience: What it means, why it matters, and how to promote it. Academic Medicine, 88(3), 301-303. DOI 10.1097/ACM.0b013e318280cff0.

17. Jeon, H. J., Bang, Y. R., Park, H. Y., Kim, S. A., Yoon, I. (2017). Differential effects of circadian typology on sleeprelated symptoms, physical fatigue and psychological well-being in relation to resilience. Chronobiology International, 34(6), 677-686. DOI 10.1080/07420528.2017.1309425.

18. Kitamura, H., Shindo, M., Tachibana, A., Honma, H., Someya, T. (2013). Personality and resilience associated with perceived fatigue of local government employees responding to disasters. Journal of Occupational Health, 55(1), 1-5. DOI 10.1539/joh.12-0095-BR.

19. Alsharif, A. (2020). The protective role of resilience in emotional exhaustion among dental students at clinical levels. Psychology Research and Behavior Management, 13, 995-558.

20. Fang, J., Qiu, C., Xu, H., You, G. (2013). A model for predicting acute and chronic fatigue in Chinese nurses. Journal of Advanced Nursing, 69(3), 546-558. DOI 10.1111/j.1365-2648.2012.06029.x.

21. Trinkoff, A. M., Storr, C. L., Lipscomb, J. A. (2001). Physically demanding work and inadequate sleep, pain medication use, and absenteeism in registered nurses. Journal of Occupational \& Environmental Medicine, 43(4), 355-363. DOI 10.1097/00043764-200104000-00012.

22. Lowe, L. D. (2013). Creating a caring work environment and fostering nurse resilience. International Journal for Human Caring, 17(4), 52-59. DOI 10.20467/1091-5710.17.4.52.

23. Herrman, H., Stewart, D. E., Diaz-Granados, N., Berger, E. L., Jackson, B. et al. (2011). What is resilience? Canadian Journal of Psychiatry, 56(5), 258-265. DOI 10.1177/070674371105600504.

24. Eisenberger, R., Huntington, R., Hutchison, S., Sowa, D. (1986). Perceived organizational support. Journal of Applied Psychology, 71(3), 500-507. DOI 10.1037/0021-9010.71.3.500.

25. Priyatama, A. N., Zainuddin, M., Handoyo, S. (2018). The influence of self-efficacy, optimism, hope and resilience on work engagement: Role of perceived organizational support as mediator. Journal of Educational, Health and Community Psychology, 7(1), 61-77. DOI 10.12928/jehcp.v7i2.8540.

26. Wright, P. J., Kim, P. Y., Wilk, J. E., Thomas, J. L. (2012). The effects of mental health symptoms and organizational climate on intent to leave the military among combat veterans. Military Medicine, 177(7), 773-779. DOI 10.7205/MILMED-D-11-00403.

27. Rhoades, L., Eisenberger, R. (2002). Perceived organizational support: A review of the literature. Journal of Applied Psychology, 87(4), 698-714. DOI 10.1037/0021-9010.87.4.698.

28. Kim, J., Jang, S. (2018). Seafarers' quality of life: Organizational culture, self-efficacy, and perceived fatigue. International Journal of Environmental Research and Public Health, 15(10), 2150. DOI 10.3390/ijerph15102150.

29. Allen, S. M. (2010). The relationship between perceived levels of organizational support and levels of compassion fatigue and compassion satisfaction among child welfare workers. (Ph.D. Dissertation), Capella University, Minneapolis.

30. Hobfoll, S. E. (2002). Social and psychological resources and adaptation. Review of General Psychology, 6(4), 307-324. DOI 10.1037/1089-2680.6.4.307. 
31. Al-Omar, H. A., Arafah, A. M., Barakat, J. M., Almutairi, R. D., Khurshid, F. et al. (2019). The impact of perceived organizational support and resilience on pharmacists' engagement in their stressful and competitive workplaces in Saudi Arabia. Saudi Pharmaceutical Journal, 27(7), 1044-1052. DOI 10.1016/j.jsps.2019.08.007.

32. Liu, L., Hu, S., Wang, L., Sui, G., Ma, L. (2013). Positive resources for combating depressive symptoms among Chinese male correctional officers: Perceived organizational support and psychological capital. BMC Psychiatry, 13(1), 89. DOI 10.1186/1471-244X-13-89.

33. Liu, L., Wen, F., Xu, X., Wang, L. (2015). Effective resources for improving mental health among Chinese underground coal miners: Perceived organizational support and psychological capital. Journal of Occupational Health, 57(1), 58-68. DOI 10.1539/joh.14-0082-OA.

34. Liu, L., Wu, F., Wang, L., Qu, Y., Wu, H. (2020). Effort-reward imbalance, resilience and perceived organizational support: A moderated mediation model of fatigue in Chinese nurses. Risk Management and Healthcare Policy, 13, 893-901.

35. Ling, W., Yang, H., Fang, L. (2006). Perceived organizational support (POS) of the employees. Acta Psychologica Sinica, 38(2), 281-287.

36. Yu, X., Zhang, J. (2007). A comparison between the Chinese version of Ego-Resiliency Scale and ConnorDavidson Resilience Scale. Psychological Science, 30(5), 1169-1171.

37. Frone, M. R., Tidwell, M. C. O. (2015). The meaning and measurement of work fatigue: Development and evaluation of the three-dimensional work fatigue inventory (3D-WFI). Journal of Occupational Health Psychology, 20(3), 273-288. DOI 10.1037/a0038700.

38. Chu, K., She, S. (2016). Reliability and validity of the three-dimensional work fatigue inventory. Modern Preventive Medicine, 46(1), 99-101,120.

39. Anderson, J. C., Gerbing, D. W. (1988). Structural equation modeling in practice: A review and recommended two-step approach. Psychological Bulletin, 103(3), 411-423. DOI 10.1037/0033-2909.103.3.411.

40. Gerbing, D. W., Anderson, J. C. (1988). An updated paradigm for scale development incorporating unidimensionality and its assessment. Journal of Marketing Research, 25(2), 186-192. DOI 10.1177/ 002224378802500207.

41. Ríos Rísquez, M. I., Carrillo Garcia, C., Sabuco Tebar, E. D. L. A. (2012). Resilience and burnout syndrome in nursing students and its relationship with sociodemographic variables and interpersonal relationship. International Journal of Psychological Research, 5(1), 88-95. DOI 10.21500/20112084.765.

42. Jin, C. H., Sook, J. M. (2014). Effect of empathy, resilience, self-care on compassion fatigue in oncology nurses. Journal of Korean Academy of Nursing Administration, 20(4), 373-382. DOI 10.11111/jkana.2014.20.4.455.

43. Tugade, M. M., Fredrickson, B. L. (2004). Resilient individuals use positive emotions to bounce back from negative emotional experiences. Journal of Personality and Social Psychology, 86(2), 320-333. DOI 10.1037/ 0022-3514.86.2.320.

44. Gillespie, B. M., Chaboyer, W., Wallis, M., Grimbeek, P. (2007). Resilience in the operating room: Developing and testing of a resilience model. Journal of Advanced Nursing, 59(4), 427-438. DOI 10.1111/j.13652648.2007.04340.x.

45. Schmidt, M., Haglund, K. (2017). Debrief in emergency departments to improve compassion fatigue and promote resiliency. Journal of Trauma Nursing: Official Journal of the Society of Trauma Nurses, 24(5), 317-322. DOI 10.1097/JTN.0000000000000315.

46. Liang, H. F., Wu, K. M., Hung, C. C., Wang, Y. H., Peng, N. H. (2019). Resilience enhancement among student nurses during clinical practices: A participatory action research study. Nurse Education Today, 75(3), 22-27. DOI 10.1016/j.nedt.2019.01.004.

47. Babanataj, R., Mazdarani, S., Hesamzadeh, A., Gorji, M. H., Cherati, J. Y. (2019). Resilience training: Effects on occupational stress and resilience of critical care nurses. International Journal of Nursing Practice, 25(1), e12697. DOI 10.1111/ijn.12697.

48. Hart, P., Brannan, J. D., De Chesnay, M. (2014). Resilience in nurses: An integrative review. Journal of Nursing Management, 22(6), 720-734. DOI 10.1111/j.1365-2834.2012.01485.x. 
49. Ku, C. H., Smith, M. J. (2010). Organisational factors and scheduling in locomotive engineers and conductors: Effects on fatigue, health and social well-being. Applied Ergonomics, 41(1), 62-71. DOI 10.1016/j. apergo.2009.04.006.

50. Liu, H., Fan, J. (2017). Organizational support and work-related fatigue: The mediating role of intrinsic motivation. Industrial Engineering and Management, 22(2), 153-159.

51. Sihag, P., Sarikwal, L. (2015). Effect of perceived organizational support on psychological capital: A study of IT industries in Indian framework. Electronic Journal of Business Ethics and Organization Studies, 20(2), 19-26.

52. Liu, Y., Wu, L. M., Chou, P. L., Chen, M. H., Yang, L. C. et al. (2015). The influence of work-related fatigue, work conditions, and personal characteristics on intent to leave among new nurses. Journal of Nursing Scholarship, 48(1), 66-73. DOI 10.1111/jnu.12181.

53. Teng, Z., Wei, Z., Qiu, Y., Tan, Y., Chen, J. et al. (2020). Psychological status and fatigue of frontline staff two months after the COVID-19 pandemic outbreak in China: A cross-sectional study. Journal of Affective Disorders, 275, 247-252. DOI 10.1016/j.jad.2020.06.032.

54. Polit, D. F., Beck, C. T. (2004). Nursing research: Principles and methods. 7th edition. Philadelphia, PA: Lippincott Williams \& Wilkins. 